\title{
Genomic Organization, Expression Analysis, and Chromosomal Localization of the Mouse PEX3 Gene Encoding a Peroxisomal Assembly Protein
}

\author{
Ania C. Muntau ${ }^{1}$, Peter U. Mayerhofer ${ }^{1}$, \\ Sabrina Albet ${ }^{2}$, Thomas E. Schmid ${ }^{3}$, \\ Maurice Bugaut ${ }^{2}$, Adelbert A. Roscher ${ }^{1, *}$ \\ and Stefan Kammerer ${ }^{1, a}$ \\ ${ }^{1}$ Dr. von Hauner Children's Hospital, \\ Laboratory of Molecular Biology, \\ Ludwig-M aximilians-University, Lindwurmstr. 4, \\ D-80337 Munich, Germany \\ ${ }^{2}$ Laboratoire de Biologie M oléculaire et Cellulaire, \\ Faculté des Sciences Mirande, F-21000 Dijon, France \\ ${ }^{3}$ GSF - National Research Center for Environment \\ and Health, Institute of Mammalian Genetics, \\ D-85764 Neuherberg, Germany \\ ${ }^{*}$ Corresponding author
}

The peroxin Pex3p has been identified as an integral peroxisomal membrane protein in yeast where pex3 mutants lack peroxisomal remnant structures. Although not proven in higher organisms, a role of this gene in the early peroxisome biogenesis is suggested. We report here the CDNA cloning and the genomic structure of the mouse PEX3 gene. The 2 kb cDNA encodes a polypeptide of 372 amino acids (42 kDa). The gene spans a region of $30 \mathrm{~kb}$, contains 12 exons and 11 introns and is located on band $A$ of chromosome 10. The putative promoter region exhibits characteristic housekeeping features. PEX3 expression was identified in all tissues analyzed, with the strongest signals in liver and in testis, and could not be induced by fenofibrate. The data presented may be useful for the generation of a mouse model defective in PEX3 in order to clarify the yet unknown functional impact of disturbances in early peroxisomal membrane assembly. Key words: Chromosomal localization / Fenofibrate induction / Peroxin / Peroxisomal biogenesis / Peroxisomal ghost/ Tissue expression.

Peroxisome biogenesis includes peroxisome proliferation, membrane biogenesis and peroxisomal matrix protein import (Subramani et al., 1997). Proteins involved in

\footnotetext{
a Present address: SEQUENOM Inc., 11555 Sorrento Valley Road, San Diego, CA 92121, USA.
}

the assembly of peroxisomes are encoded by PEX genes and are termed peroxins (Distel et al., 1996). While at least 23 peroxins have been reported to be essential for peroxisome biogenesis, the exact functions and interactions of only a limited number of these proteins have been determined so far. Data from yeast suggested that the PEX3 gene codes for an integral membrane protein essential for both peroxisomal membrane assembly and membrane protein import (Höhfeld et al., 1991; Snyder et al., 1999b). In a previous study we cloned and characterized the human PEX3 cDNA (Kammerer et al., 1998). Pex3p has been shown to interact with Pex19p in yeast (Götte et al., 1998; Snyder et al., 1999a), and in humans (Soukupova et al., 1999). Saccharomyces cerevisiae cells deficient in either Pex3p or Pex19p were reported to lack peroxisomal remnant structures, also called peroxisomal ghosts (Götte et al., 1998). These observations and the recent identification of multimeric peroxisomal assembly protein complexes are consistent with the hypothesis that these two proteins are essential players in peroxisomal membrane biogenesis and peroxisomal membrane protein localization (Snyder et al., 1999b). However, the precise contribution of these peroxins to the maturation of early peroxisomes and human disease pathogenesis is notyet known. The generation of mice with targeted disruption of early peroxin genes, such as PEX3, is expected to deliver more information about biological relevance and function. We report here the cDNA sequence and expression data as well as the analysis of the genomic structure and the chromosomal localization of the mouse PEX3 gene.

The expressed sequence tag (EST) database dbEST (Boguski et al., 1993) was probed with the human PEX3 cDNA sequence. Four mouse EST clones, m1 (IMAGp998L081096), m2 (IMAGp998H081406), m3 (IMAG p998P072169), and m4 (IMAGp998M232137) were obtained from the Resource Center of the German Human Genome Project (Lehrach et al., 1990). The longest clone, $\mathrm{ml}$, was completely sequenced and revealed to contain 1511 bp including the $3^{\prime}$ portion of the gene. The CDNA was completed by 5' RACE-PCR (Marathon-Ready mouse liver cDNA, Clontech) and showed the following features: a 5' untranslated region of 167 bp followed by an open reading frame of $1116 \mathrm{bp}$ (372 amino acids) and a 3 ' untranslated sequence of $729 \mathrm{bp}$. A consensus poly(A) signal was identified $34 \mathrm{bp}$ upstream of the poly $(A)$ at position +2017 relative to the transcription start site. The usage of an alternative poly(A) site in the $3^{\prime}$ untranslated 
region was confirmed by $3^{\prime}$ RACE-PCR. Two further poly(A) signals at positions +1341 and +1376 were detected in several clones followed by a poly(A)tail $16-35 \mathrm{bp}$ downstream. The position of the two alternative poly $(A)$ sites at about 70 and 730 bp downstream of the TGA stop codon is in agreement with the data on the human PEX3 gene (Kammerer et al., 1998). Using the ClustalW program (Thompson et al., 1994) from the Baylor College of Medicine, we performed a pairwise alignment of the deduced murine Pex3p with the human Pex3p sequence. These two proteins revealed an overall amino acid identity of $93.8 \%$. The degree of identity to the Pex 3 proteins of other species is $22.3 \%$ to Pichia pastoris ( 455 amino acids), $20.9 \%$ to Hansenula polymorpha (457 amino acids), $19.9 \%$ to Saccharomyces cerevisiae (441 amino acids), and $18.6 \%$ to Kluyveromyces lactis (483 amino acids). Protein similarity scores were determined using the Align program from EERIE (Nimes, France). A comparative analysis of Pex 3 proteins using the TMpred server of the Bioinformatics group at ISREC (Epalinges, Switzerland) predicted two hydrophobic transmembrane regions that are located in the $\mathrm{N}$-terminal half of the protein in all species.

To determine the exon-intron structure of the mouse PEX3 gene, a 129/Ola mouse genomic DNA cosmid library was screened with a mouse cDNA probe. One positive clone, mcos3, covering about $17 \mathrm{~kb}$ of the PEX3 gene including exon 3 to exon 12 was isolated. To amplify the introns, multiple exon-exon $P C R$ reactions were performed using mcos3 cosmid DNA, mouse genomic DNA from $129 / 0$ la mouse embryonic stem cells or both as a template. Exons 1 and 2, which were not present on the clone mcos3, were exclusively amplified from mouse genomic DNA. Overlapping fragments spanning the complete cod- ing region were generated and sequenced from either end using the amplification primers in order to identify the intron-exon boundaries. Comparison of the obtained genomic sequence with the CDNA sequence revealed that the mouse PEX 3 gene consists of 12 exons and 11 introns (Figure 1). The exon sizes range from $44 \mathrm{bp}$ (exon 4 ) to 166 bp (exon 8). All exon-intron junctions conform to the GT$A G$ rule (Figure 2). Five introns (intron 4, 5, 6, 7, and 9) were fully sequenced and the exon-flanking intronic sequences of all other introns were determined. The approximate sizes of introns not fully sequenced were estimated by agarose gel electrophoresis of the corresponding PCR products. The total size of the mouse PEX3 gene is approximately $30 \mathrm{~kb}$ (Figure 1 ).

To characterize the putative promoter region, $2 \mathrm{~kb}$ of genomic sequence immediately upstream of the transcriptional startsequence were obtained by long template PCR. Analysis of this 5' flanking sequence for consensus promoter elements was performed using the Transcription Factor Database (TFD) (Ghosh et al., 1991) and the Signal Scan server of BIMAS (Prestridge et al., 1991). Canonical TATA and CCAAT boxes, as a characteristic feature of housekeeping genes which are expressed at low levels in essentially all tissues, were not found. The region close to the transcription initiation site was shown to be relatively GC-rich, exhibiting a GC content of about $60 \%$ from -250 to -1 . This sequence contains a putative binding site for the transcription factor Sp1 at -30 to -25 , which was found with identical sequence and similar location in the orthologous human gene (Muntau, unpublished). At approximately $1.8 \mathrm{~kb}$ upstream of the transcription start site we detected a polymorphic CT repeat. By analyzing several subclones, repeat lengths between 17 and 27 - with the exception of 21 and 22 repeats - were identified.

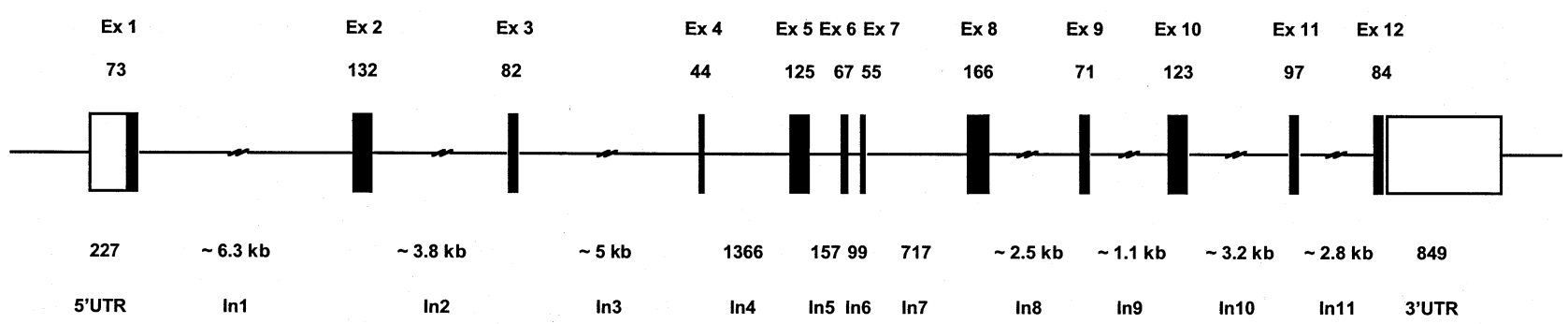

kb

Fig. 1 Genomic Organization of the M ouse PEX3 Gene.

The gene consists of twelve exons (closed boxes) and eleven introns (solid lines between the exons). Exon sizes in base pairs are indicated above, intron sizes below the horizontal line. The 5' and 3' UTRs are shown as open boxes.

Methods: mouse cosmid DNA was prepared using ion exchange column purification (M idiprep Kit, Qiagen). Multiple exon-exon PCR reactions were performed using mcos 3 cosmid DNA, mouse genomic DNA from 129/0 la mouse embryonic stem cells or both as a template. The resulting PCR products were sequenced from either end using the amplification primers. The sequence containing the putative promoter region was obtained by long template PCR (Expand Long Template PCR System, Boehringer Mannheim) using adaptor-ligated genomic DNA fragments (Mouse Genome Walker Kit, Clontech) according to the manufacturer's procedure. Two successive PCR reactions were performed using the anchor-specific primer AP 1 and a mouse PEX3-specific reverse primer (m128, 5'-ACT GTG CCC AGG AAG ATG C $-3^{\prime}$ ), and then AP 2 combined with a nested reverse primer from the coding region (m81, 5'-CCA CAT TGA TCT CAG CAT CTC C- $3^{\prime}$ ). The PCR products obtained were purified from the gel (QIAquick Gel Extraction Kit, Qiagen), directly sequenced by fluorescent dye terminator technology and separated on an ABI 377 sequencer. EMBL/GenBank sequence accession numbers: AF152996 and AF162890 through AF162896. 
Intron

\begin{tabular}{|c|c|c|c|c|c|}
\hline & & & \multirow{2}{*}{ Intron } & \multirow{2}{*}{ 3' splice site (acceptor) } & \\
\hline & & 5' splice site (donor) & & & \\
\hline Mm & CTCGGAG & GTGAGTTGACAACA & $---\operatorname{In} 1---$ & TTTAАTGATTTTAG & GAGTATA \\
\hline $\mathrm{H} \mathbf{s}$ & CTTGGAG & GTGGGTGACAACGT & $---\operatorname{In} 1-\ldots$ & TTTAATGATTGTAG & GAGTATA \\
\hline Mm & ATGACAG & GTAAGCATGCGCGC & $---\operatorname{In} 2-\cdots$ & CTGTTGAAAAGCAG & TGCTGTC \\
\hline $\mathrm{Hs}$ & ATGACAG & GTAAGACAGGGAGA & $---\operatorname{In} 2-\ldots$ & TGTTTGTATTACAG & TGCTGTC \\
\hline Mm & AAAGCAG & GTGAAAGCGCACTG & $---\operatorname{In} 3---$ & АTTTTTTTCTTTAG & $\overline{\text { GCCTTCA }}$ \\
\hline H S & AAAACAG & GTAAATGCAAGTTA & $\ldots-\operatorname{In} 3 \ldots$ & АTTTTGTTCTTTAG & GCCTTCA \\
\hline $\mathrm{Mm}$ & ATAATAA & GTAAGTCCAAATAT & $---\operatorname{In} 4---$ & TCTTCTCTCTGAAG & GTTTCAC \\
\hline $\mathrm{Hs}$ & ATAATAA & GTAAGCCTGCATAT & $---\operatorname{In} 4-\ldots$ & TTTTCTCTGTGAAG & GTTTCAC \\
\hline Mm & TGGCACT & GTAAGTTTAACAGA & $---\operatorname{In} 5---$ & TTCTGTTTGCACAG & ACCGTTC \\
\hline $\mathrm{Hs}$ & TGGCACT & GTAAGTTTAATAGA & $---\operatorname{In} 5 \ldots$ & TCTGTTTTATACAG & ACAATTC \\
\hline Mm & GGAGACG & GTAAGATTCCAGTC & $---\operatorname{In} 6---$ & TTTTTGTTTGATAG & GCCTCAC \\
\hline H s & GGAGATG & GTAAGATTCTTATT & $---\operatorname{In} 6---$ & TTTTTCTTTAATAG & GCCTGAC \\
\hline Mm & TAGGAAG & GTATGCTATGTCCT & $---\operatorname{In} 7---$ & TCСТСТАТTTCCAG & TGTCTCT \\
\hline $\mathbf{H s}$ & TAGGAAG & GTAAGGCATTTTTC & $---\operatorname{In} 7-\ldots$ & TTCTCTGTTTCTAG & TGTTTCT \\
\hline Mm & AGCTCAG & GTACTTAATTCATA & $---\operatorname{In} 8---$ & TTTTGATTTTACAG & GCCTATG \\
\hline $\mathbf{H s}$ & AGTGCAG & GTGCTTAATTCATA & $---\operatorname{In} 8$ - - & TTTTAATTCTATAG & GCCTGTG \\
\hline Mm & TGGAAAG & GTATGTAGAGTGCA & $---\operatorname{In} 9--$ & СTTTTTTTATCTAG & TCCAGAT \\
\hline $\mathbf{H} \mathbf{s}$ & TGGAAAG & GTATGTATACTTCA & $--\operatorname{In} 9-\ldots$ & СTTACTTTATATAG & CCCAGAT \\
\hline $\mathrm{Mm}$ & TAAACAG & GTAACTTGGAATGT & $---\operatorname{In} 10--$ & TAATTTGTTTTCAG & TCTGTCC \\
\hline Hs & TGAATAG & GTAAGATGACATAT & $---\operatorname{In} 10--$ & TAATGATTTTTCAG & TCTTTCC \\
\hline Mm & TGTGCAG & GTAAGTGAGAAGCT & $---\operatorname{In} 11--$ & ATGGTTGTTACCAG & GATCTGC \\
\hline Hs & TGTTCAG & GTAAGAAGAAAGCT & $---\operatorname{In} 11--$ & ATCATCTTTGCTAG & GATCTGT \\
\hline $\mathrm{Cs}$ & & $\begin{array}{l}\text { GTAAGT } \\
\mathrm{G}\end{array}$ & & $\begin{array}{l}\text { TTTTTTTTTTNCAG } \\
\text { СССССССССС }\end{array}$ & \\
\hline
\end{tabular}

Fig. 2 Comparison of the Exon-Intron Boundaries of the Mouse and Human PEX3 Gene.

The consensus sequences (CS) of the $5^{\prime}$ and $3^{\prime}$ intron splice sites are given below, where $\mathrm{N}$ is any nucleotide and, where two nucleotides are given, the one above is more common (Shapiro and Senapathy, 1987).

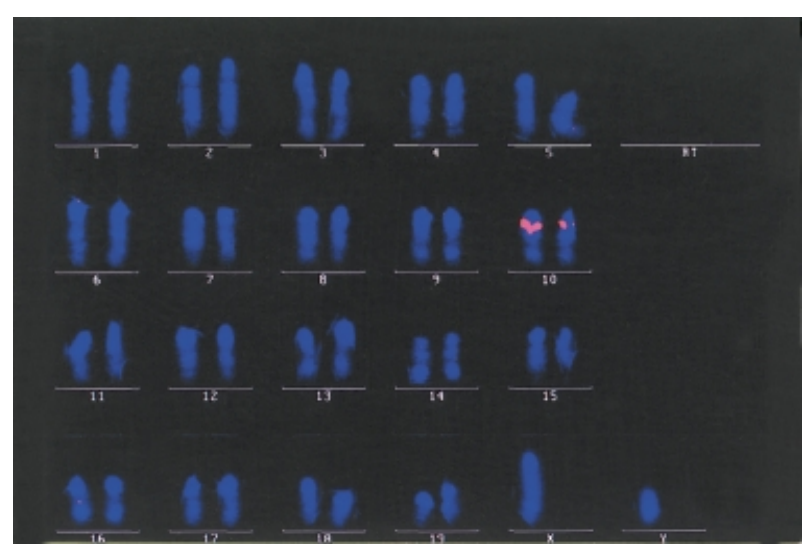

Fig. 3 Chromosomal Localization of the Mouse PEX3 Gene. Specific hybridization signals were identified on band $A$ of chromosome 10 using fluorescence in situ hybridization of metaphase chromosomes.

Methods: metaphase chromosome preparations were obtained from mouse bone marrow cells according to standard procedures. The cosmid clone mcos3, containing about $17 \mathrm{~kb}$ of the murine PEX3 gene, was labeled with biotin-14-dUTP (Life Technologies) by nick-translation and was detected with streptavidinCy3 (Amersham Life Science). Metaphase chromosomes were analyzed under an Axioppgot microscope (Zeiss) and pictures were taken by digitizing the microscopic image with the computer program ISIS3 (Metasystems).
A visual inspection of the promoter region for possible peroxisome proliferator-responsive elements (PPRE) or oleate-responsive elements (ORE) did not reveal motifs that show a strong similarity to the consensus sequences (Zhang et al., 1992; Karpichev et al., 1997).

The chromosomal localization of the PEX3 gene was determined by fluorescence in situ hybridization (FISH) analysis. The cosmid clone mcos3, containing about 17 $\mathrm{kb}$ of the mouse PEX3 gene, was labeled with biotin. By hybridization of this probe to mouse metaphase chromosomes, PEX3 was localized to band A on chromosome 10 (Figure 3 ). This region has syntenic relationship with the human chromosome region $6 q 23-6 q 24$ where the human PEX3 gene has been located by FISH analysis (Muntau, unpublished) and by large-scale genome sequencing (NCBI, GenBank accession number AL031320).

PEX3 mRNA expression in various mouse tissues was examined by Northern blot analysis using a $1.6 \mathrm{~kb}$ mouse CDNA as a probe. A human actin probe was used as control for the loaded amount of RNA. The presence of PEX3specific mRNA in all tissues examined, with the strongest expression in liver and testis, was demonstrated. In heart, brain, spleen, lung, liver, skeletal muscle, and kidney, signals at 1.6 and $2.3 \mathrm{~kb}$ were detected, with the $2.3 \mathrm{~kb}$ signal being predominant in these tissues (Figure 4). These frag- 


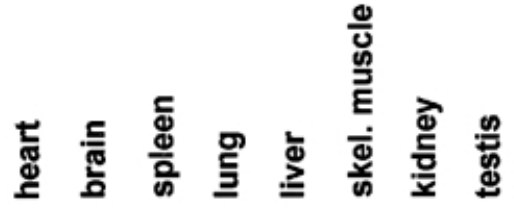

PEX3

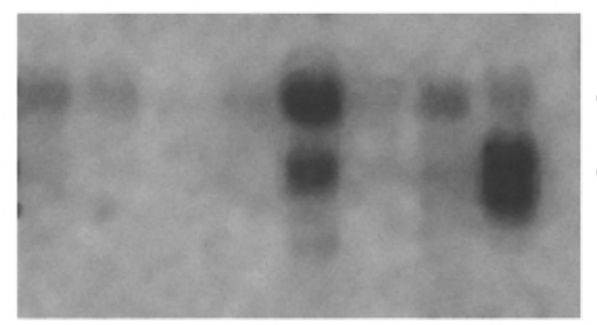

kb

$-2.3$

$-1.6$

Actin

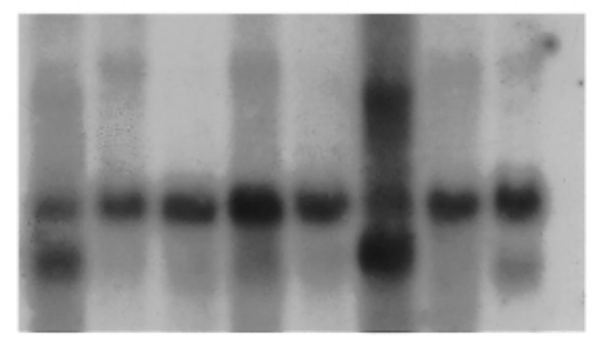

Fig. 4 Expression of the PEX3 Gene in Various Mouse and Rat Tissues.

A Northern blot of mRNA from several murine tissues was hybridized with the $1.6 \mathrm{~kb}$ mouse cDNA probe. A human actin probe was used as control for the loaded amount of RNA. Fragment sizes are indicated on the right.

Methods: PEX3 mRNA expression in various mouse tissues was examined using a BALB/C mouse multiple tissue Northern blot containing $2 \mu \mathrm{g}$ poly $(\mathrm{A})^{+}$mRNA per lane (Clontech). A $1.6 \mathrm{~kb}$ CDNA fragment was isolated with Notl and Xhol from the mouse EST clone $\mathrm{m} 1$ and radiolabeled with $\left[\alpha-{ }^{32} \mathrm{P}\right] \mathrm{dATP}$ by random priming. The blot was hybridized as described elsewhere (Braun et al., 1994) and exposed to an X-ray film for 10 days. Signals obtained were compared to those detected by a human actin cDNA probe.

ments seem to be derived from alternative polyadenylation at $+1341 / 1376$ and +2017 bp described above. In testis, in addition to the $2.3 \mathrm{~kb}$ transcript several shorter fragments were observed with lengths between 1.4 and $1.7 \mathrm{~kb}$. This was the only tissue in which the shorter transcripts were expressed at a higher intensity. It might be interesting to note that a marked morphological heterogeneity of peroxisomes has been described in cultured mouse testicular Leydig cells (Litwin and Bilinska, 1995). PEX3 might potentially be involved in the formation of small local networks of interconnected tubular peroxisomes observed in this study.

Pharmacological modification of the expression levels of specific peroxins might be a valuable addition to treatment strategies for human peroxisomal biogenesis disorders. Fenofibrate, which was proven to be a potent peroxisomal proliferator in rodents, is a broad-spectrum lipidlowering agent widely used in patients with coronary heart disease (Packard et al., 1998). To compare PEX3 mRNA expression in rats before and after fenofibrate treatment, Northern blot analysis of rat tissues using a human $2.1 \mathrm{~kb}$ PEX3 probe was performed. Signals obtained were com- pared to those detected with a rat glyceraldehyde-3phosphate dehydrogenase (GAPDH) control probe. As a positive control for the effectiveness of the fenofibrate treatment, hybridization with a mouse acyl-CoA oxidase (AOX) probe was performed. As in the mouse, PEX3-specific mRNA in rat was also expressed in all tissues examined. The amount of lower transcript was slightly increased in liver but overall the transcripts showed a more even distribution than in mouse (Figure 5). The examination of rat testis tissue has still to be performed. The fenofibrate-treatment did not affect the level of PEX3 mRNA expression, indicating that transcription of PEX3 is not induced by fenofibrate in rats (Figure 5 ). In contrast, the level of peroxisomal acyl-COA oxidase (AOX) mRNA used as a marker of peroxisomal proliferation was strongly enhanced in liver, kidney, intestine and heart, proving the effectiveness of fenofibrate treatment (Figure 5). Fenofibrate is known to strongly increase the level of peroxisome proliferator activated receptors in rats (Gebel et al., 1992). Interestingly, the mouse promoter does not exhibit can-
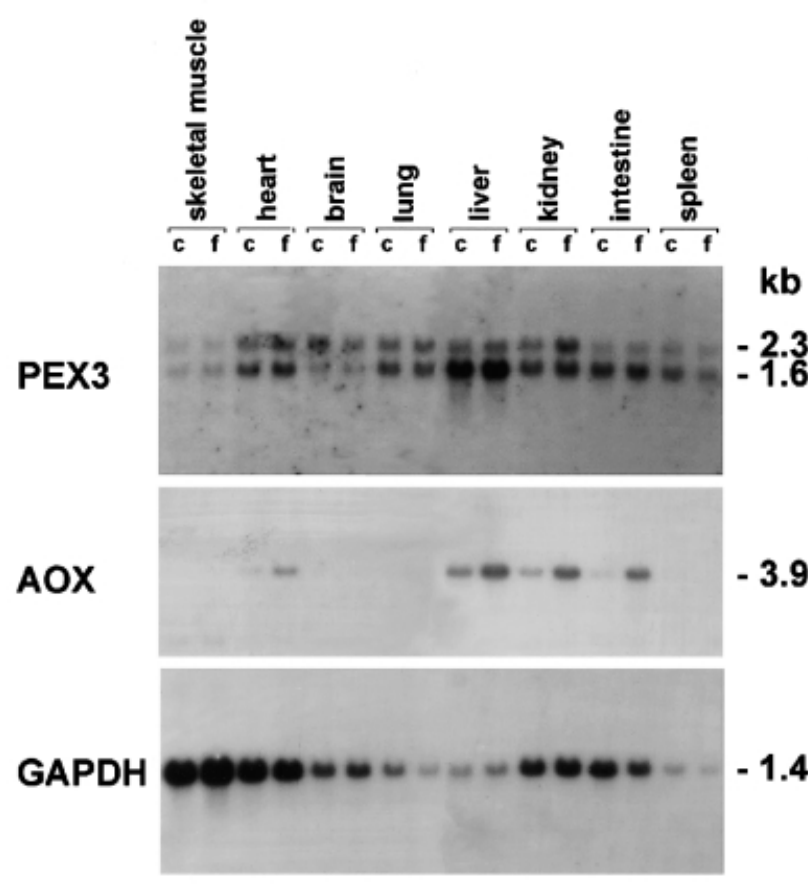

Fig. 5 Northern Blot Analysis in Various Tissues from Fenofibrate-Treated and Untreated Rats.

Hybridization was performed using the $2.1 \mathrm{~kb}$ human PEX 3 CDNA probe. Signals obtained were compared to those detected with a rat glyceraldehyde-3-phosphate dehydrogenase (GAPDH) control probe. The level of peroxisomal acyl-CoA oxidase (AOX) mRNA was used as marker for peroxisomal proliferation. Fragment sizes are indicated on the right. c: untreated, f: fenofibratetreated rats.

Methods: Northern blot analysis of rattissues using a human $2.1 \mathrm{~kb}$ PEX3 probe was performed as previously described (Albet et al., 1997). Signals obtained were compared to those detected with a rat glyceraldehyde-3-phosphate dehydrogenase (GAPDH) control probe. As a positive control for the effectiveness of the fenofibrate treatment, hybridization with a mouse acyl-CoA oxidase (AOX) probe prepared from a $246 \mathrm{bp}$ coding fragment was performed as described elsewhere (Albet et al., 1997). 
onical peroxisome proliferator-responsive elements. Assuming that this is also the case in rat, this might explain the lack of induction of rat PEX3 by fenofibrate. It has been reported previously that fenofibrate strongly induced the expression of two other peroxisomal membrane proteins of the ABC-transporter superfamily, P M P 70p and ALDRp, in rat and mouse (Albet et al., 1997; Holzinger et al., 1998; Berger et al., 1999). These data are in agreement with the hypothesis that proteins which are directly or ind irectly involved in peroxisomal metabolism are pharmacologically inducible, whereas proteins involved in the peroxisomal biogenesis, such as Pex3p, can not be induced. Confirmation of these findings would have important consequences for the development of new treatment strategies.

Based on the findings in yeast, PEX3 is a candidate gene for human peroxisomal biogenesis disorders. PEX3 mutations have not been identified so far. Among the considerable number of PEX genes, mouse models have only been described for PEX2, which encodes a zinc-binding integral membrane protein (Faust and Hatten, 1997), and PEX5, which encodes the import receptor for most peroxisomal matrix proteins (Baes et al., 1997). However, a mouse model with targeted disruption of one of the PEX genes involved in the initial steps of peroxisomal biogenesis is not yet available. The data reported here might contribute to further elucidation of the basic aspects of formation and function of peroxisomes, and help to develop treatment strategies for peroxisomal biogenesis disorders, which are still leading to early death in affected children.

\section{Acknowledgements}

We wish to thank Dr. Ennes Auerswald for the opportunity to use the sequencing facility and Heide Hinz for excellent technical assistance. We are grateful to Dr. Andreas Holzinger for helpful discussions and for critical reading of the manuscript. This work was supported by a grant from the Deutsche Forschungsgemeinschaft (R0 727/1-1).

\section{References}

Albet, S., Causeret, C., Bentejac, M., Mandel, J .L., Aubourg, P., and Bugaut, M. (1997). Fenofibrate differently alters expression of genes encoding ATP-binding transporter proteins of the peroxisomal membrane. FEBS Lett. 405, 394 - 397.

Baes, M., Gressens, P., Baumgart, E., Carmeliet, P., Casteels, M., Fransen, M., Evrard, P., Fahimi, D., Declercq, P.E., Collen, D., van Veldhoven, P.P., and Mannaerts, G.P. (1997). A mouse model for Zellweger syndrome. Nature Genet. 17, 49- 57.

Berger, J ., Albet, S., Bentejac, M., Netik, A., Holzinger, A., Roscher, A.A., Bugaut, M., and Forss-Petter, S. (1999). The four murine peroxisomal $A B C$-transporter genes differ in constitutive, inducible and developmental expression. Eur. J . Biochem. 265, $719-727$.

Boguski, M.S., Lowe, T.M., and Tolstoshev, C.M. (1993). dbESTdatabase for "expressed sequence tags". Nature Genet. 4, $332-333$.
Braun, A., Kammerer, S., Weissenhorn, W., Weiss, E.H., and Cleve, H. (1994). Sequence of a putative human housekeeping gene (HK33) localized on chromosome 1. Gene 146, 291- 295.

Distel, B., Erdmann, R., Gould, S.J ., Blobel, G., Crane, D.I., Cregg, J .M., Dodt, G., Fujiki, Y., Goodman, J .M., J ust, W.W., Kiel, J .A., Kunau, W.H., et al. (1996). A unified nomenclature for peroxisome biogenesis factors. J. Cell Biol. 135, 1 - 3.

Faust, P.L., and Hatten, M.E. (1997). Targeted deletion of the PEX2 peroxisome assembly gene in mice provides a model for Zellweger syndrome, a human neuronal migration disorder. J . Cell Biol. 139, 1293-1305.

Gebel, T., Arand, M., and Oesch, F. (1992). Induction of the peroxisome proliferator activated receptor by fenofibrate in rat liver. FEBS Lett. 309, 37- 40.

Ghosh, D. (1991). New developments of a transcription factors database. Trends Biochem. Sci. 16, 445- 447.

Götte, K., Girzalsky, W., Linkert, M., Baumgart, E., Kammerer, S., Kunau, W.H., and Erdmann, R. (1998). Pex19p, a farnesylated protein essential for peroxisome biogenesis. Mol. Cell. Biol. 18, $616-628$.

Höhfeld, J ., Veenhuis, M., and Kunau, W.H. (1991). PAS3, a Saccharomyces cerevisiae gene encoding a peroxisomal integral membrane protein essential for peroxisome biogenesis. J . Cell Biol. 114, 1167-1178.

Holzinger, A., Muntau, A.C., Mayerhofer, P., Kammerer, S., Albet, S., Bugaut, M., and Roscher, A.A. (1998). The mouse gene encoding the peroxisomal membrane protein 1-like protein (PXMP1-L): CDNA cloning, genomic organization and comparative expression studies. FEBS Lett. 433, 179-183.

Kammerer, S., Holzinger, A., Welsch, U., and Roscher, A.A. (1998). Cloning and characterization of the gene encoding the human peroxisomal assembly protein Pex3p. FEBS Lett. 429, 53-60.

Karpichev, I.V., Luo, Y., Marians, R.C., and Small, G.M. (1997). A complex containing two transcription factors regulates peroxisome proliferation and the coordinate induction of beta-oxidation enzymes in Saccharomyces cerevisiae. Mol. Cell. Biol. 17, $69-80$.

Lehrach, H. (1990). In: Genome Analysis, 1. ed. (Cold Spring Harbor, NY, USA: Cold Spring Harbor Laboratory Press), pp. $39-81$.

Litwin, J .A., and Bilinska, B. (1995). Morphological heterogeneity of peroxisomes in cultured mouse Leydig cells. Folia Histochem. Cytobiol. 33, 255- 258.

Packard, C.J . (1998). Overview of fenofibrate. Eur. Heart J . 19, A62- 65.

Prestridge, D.S. (1991). Signal Scan: a computer program that scans DNA sequences for eukaryotic transcription elements. Comput. Appl. Biosci. 7, 203-206.

Shapiro, M.B., and Senapathy, P. (1987). RNA splice junctions of different classes of eukaryotes: sequence statistics and functional implications in gene expression. Nucleic Acids Res. 15, $7155-7174$.

Snyder, W.B., Faber, K.N., Wenzel, T.J ., Koller, A., Luers, G.H., Rangell, L., Keller, G.A., and Subramani, S. (1999a). Pex19p interacts with Pex3p and Pex10p and is essential for peroxisome biogenesis in Pichia pastoris. Mol. Biol. Cell. 10, 1745-1761.

Snyder, W.B., Koller, A., Choy, A.J ., J ohnson, M.A., Cregg, J .M., Rangell, L., Keller, G.A., and Subramani, S. (1999b). Pex17p is required for import of both peroxisome membrane and lumenal proteins and interacts with pex $19 p$ and the peroxisome targeting signal- receptor docking complex in pichia pastoris. Mol. Biol. Cell. 10, $4005-4019$.

Soukupova, M., Sprenger, C., Gorgas, K., Kunau, W.H., and Dodt, G. (1999). Identification and characterization of the human peroxin PEX3. Eur. J. Cell Biol. 78, 357- 374. 
Subramani, S. (1997). PEX genes on the rise. Nature Genet. 15, $331-333$.

Thompson, J.D., Higgins, D.G., and Gibson, T.J. (1994). CLUSTAL W: improving the sensitivity of progressive multiple sequence alignment through sequence weighting, positionspecific gap penalties and weight matrix choice. Nucleic Acids Res. 22, 4673-4680.
Zhang, B., Marcus, S.L., Sajjadi, F.G., Alvares, K., Reddy, J .K., Subramani, S., Rachubinski, R.A., and Capone, J.P. (1992). Identification of a peroxisome proliferator-responsive element upstream of the gene encoding rat peroxisomal enoyl-CoA hydratase/3-hydroxyacyl-CoA dehydrogenase. Proc. Natl. Acad. Sci. USA 89, 7541-7545.

Received J anuary 12, 2000; accepted February 17, 2000 